\title{
Recursos e capacidades estratégicos em serviços médicos privados
}

A partir do objetivo de identificar que recursos e capacidades os médicos de serviços privados da cidade de Rio Verde, Goiás, têm gerido para diferenciar seus serviços e serem preferidos pelos clientes, este estudo fundamentou-se nos pressupostos da visão baseada em recursos (VBR) por ser a teoria capaz de explicar como empresas obtém vantagem competitiva a partir dos seus recursos e capacidades heterogêneos e inimitáveis. $\mathrm{O}$ trabalho adotou abordagem qualitativa descritiva em que os dados foram coletados por meio de entrevistas padronizadas e analisados com a técnica de análise de conteúdo. Foram entrevistados médicos da cidade de Rio Verde, Goiás, que já estiveram associados a algum plano de saúde e que hoje atendem exclusivamente serviços privados. Concluiu-se que os médicos entendem que isoladamente a reformulação no ambiente físico, a maior exposição do conhecimento profissional, a diferenciação do atendimento dos auxiliares e recepcionistas e a maior interação com os pacientes representam os recursos mais importantes, mas só são estratégicos, se estiverem integrados uns aos outros e se refletirem as expectativas dos clientes que pagam pelas consultas. A conexão com o mercado e o relacionamento com clientes demonstraram ser cruciais para os profissionais de serviços privados que pretendem orientar suas ofertas para o mercado, tornando-os diferenciados em comparação aos dos concorrentes.

Palavras-chave: Visão baseada em recursos; Vantagem competitiva; Recursos e capacidades estratégicos; Serviços diferenciados.

\section{Strategic resources and capacities for creating value in private medical services}

\begin{abstract}
With the objective of identifying what resources and capacities the private service physicians of the city of Rio Verde, Goiás, have managed to differentiate their services and be preferred by clients, this study was based on the assumptions of the resource-based view (RBV). This is the theory capable of explaining how companies obtain competitive advantage from their heterogeneous and inimitable resources and capacities. The study adopted a descriptive qualitative approach in which data were collected through standardized interviews. They were analyzed using the content analysis technique. Physicians from the city of Rio Verde, Goiás, who had already been associated with some health plan and now only offer private services, were interviewed. We concluded that physicians understand that in isolation reformulation in the physical environment, greater exposure of professional knowledge, differentiation of the attendance of the assistants and receptionists and greater interaction with the patients represent the most important resources, but they are only strategic if they are integrated into each other and reflect the expectations of clients who pay for consultations. Connection with the market and relationship with clients proved to be crucial for private service professionals who want to be oriented to the market, making their services differentiated in comparison to competitors.
\end{abstract}

Keywords: Resource-based view; Competitive advantage; Strategic resources and capabilities; Differentiated services.

Topic: Planejamento, Estratégia e Competitividade

Reviewed anonymously in the process of blind peer.

Leninne Freitas

Universidade de Rio Verde, Brasil

http://lattes.cnpq.br/6095186535470973

leninne@uol.com.br

Claudemir Bertuolo Furnielis

Universidade Municipal de São Caetano do Sul, Brasil

http://lattes.cnpq.br/8846786059542387

cbertuolo@uol.com.br

Giancarllo Ribeiro Vasconcelos

Universidade de Rio Verde, Brasil

http://lattes.cnpq.br/1290341447552409

giancarllo@unirv.edu.br
Received: 08/05/2017

Approved: 08/07/2017
Referencing this:

FREITAS, L.; FURNIELIS, C. B.; VASCONCELOS, G. R.. Recursos e capacidades estratégicos em serviços médicos privados. Revista Brasileira de Administração Científica, v.8, n.2, p.83-96, 2017. DOI: http://doi.org/10.6008/SPC2179-684X.2017.002.0006 


\section{INTRODUÇÃO}

Este artigo aborda recursos e capacidades estratégicos adotados por micro e pequenas empresas de serviços médicos privados da cidade de Rio Verde, Goiás, como forma de criar diferenciação para clientes, visando a obtenção de vantagem competitiva. Dentre os motivos que justificam este estudo, destaca-se que as micro e pequenas empresas têm alcançado participação cada vez maior no cenário nacional. Segundo o Instituto Brasileiro de Geografia e Estatística - IBGE, elas correspondem a 99\% dos 6 milhões de estabelecimentos formais existentes no país e respondem por mais de um quarto do Produto Interno Bruto (PIB) brasileiro e representam 27\% do PIB, de acordo com o SEBRAE. Para o Serviço de Apoio às Micro e Pequenas Empresas, são consideradas microempresas, conforme o SEBRAE, aquelas que têm até 19 empregados e pequenas empresas as que possuem entre 20 e 99 empregados.

Adequadas a esta definição estão muitas clínicas e consultórios médicos. As bases de dados do ProQuest, Jstore, Spell e Portal de Periódicos Capes apresentam um grande número de estudos sobre pequenas e médias empresas, mas são incipientes as pesquisas que tratam de consultórios médicos e de outros profissionais liberais como unidades de negócios que competem entre si e buscam se diferenciar dos concorrentes de maneira a serem preferidos pelos clientes.

No Brasil existem cerca de 268.630 estabelecimentos de saúde, conforme o Cadastro Nacional de Estabelecimentos de Saúde (CNS). A entidade aponta ainda que a área de saúde terminou o ano de 2016 com 3,1 milhões de postos de trabalho, com crescimento de 19,2\%, desde 2010 . O que chama a atenção é que do total de estabelecimentos de saúde, $13 \%$ são clínicas e $49 \%$, a maioria, trata-se de consultórios isolados (133.123).

Outro aspecto relevante do setor são os planos de saúde, que representam importante meio de serviços de assistência à saúde. Em 2016, de acordo com dados na Agência Nacional de Saúde (ANS), cerca de 48 milhões de brasileiros estiveram vinculados a algum plano de assistência médica. Apesar da recessão em 2016, o mercado de plano de saúde faturou, aproximadamente, $\mathrm{R} \$ 108 \mathrm{bi}$, cerca de $2 \%$ do Produto Interno Bruto (PIB) do Brasil.

Como já evidenciado no início, o estudo será feito na cidade de Rio Verde, Goiás, município localizado no sudoeste do Estado. Rio Verde é destaque no cenário nacional por sua grande produtividade agrícola (município mais rico em produção agropecuária), alto crescimento econômico (14,6\% ao ano) e populacional (cerca de $57 \%$ em 10 anos), segundo dados do IBGE.

No contexto da pesquisa, o principal motivo que justifica a escolha da cidade, refere-se ao fato desta ter o segundo contingente de usuários de planos privados financiadores de saúde em Goiás (30\% da população), índice acima da média nacional (25\%), e ser considerável o número de profissionais não credenciados por planos de saúde, ou seja, que atendem preferencialmente clientes privados, conforme dados da AMERV (2016).

Se de um lado, os planos de saúde têm sido um dos grandes responsáveis pela expansão significativa de serviços e negócios no mercado da saúde, do outro, há reivindicações, conforme ressalta a BBC Brasil, do valor pago pelas operadoras de saúde por consultas e procedimentos, considerado "incipiente" por 
organizações médicas e por profissionais. De acordo com ANS, já é realidade a migração de profissionais que atendem pelas operadoras de saúde para o atendimento particular. Assim, surgem as seguintes indagações: como os médicos não credenciados por planos de saúde diferenciam seus serviços de modo a serem preferidos pelos clientes? Então, que recursos e capacidades os médicos de serviços privados gerem para diferenciar seus serviços?.

Para responder a esses questionamentos, serão utilizadas as abordagens da visão baseada em recursos (VBR) para a gestão de recursos e capacidades por apresentar fundamentação teórica suficiente para identificar e descrever os constructos envolvidos nas respostas. A VBR é uma das abordagens mais expressivas da administração estratégica que vê a empresa como um conjunto de recursos e capacidades como fontes geradoras de vantagem competitiva (BARNEY, 1991). Em essência, para a VBR, uma empresa é capaz de obter vantagem competitiva quando consegue criar mais valor econômico para o cliente por meio dos recursos e capacidades que seus competidores (BARNEY et al., 2003).

Com base na VBR e para responder a pergunta de pesquisa, o artigo tem como objetivo geral identificar que recursos e capacidades os médicos de serviços privados da cidade de Rio Verde, Goiás, têm gerido para diferenciar seus serviços e serem preferidos pelos clientes e está estruturado, na sequência, em quatro etapas. Na primeira, encontra-se a fundamentação teórica abordando a VBR com as definições de criação de valor e recursos e capacidades. Na segunda, estão apresentados os procedimentos metodológicos que dão suporte ao estudo; na terceira etapa, apresenta-se os resultados da pesquisa, com discussão à luz do referencial teórico e por fim, na quarta, expõe-se a conclusão do trabalho.

\section{REVISÃO TEÓRICA}

\section{Visão baseada em recursos e a criação de valor}

A Visão Baseada em Recursos (VBR) tem sua origem com Penrose (1959) ao descrever que uma empresa é mais do que uma unidade administrativa, é um conjunto de recursos produtivos disponíveis para diversos usos e ao longo do tempo, determinado por decisões administrativas. Semelhante ao que propõe a autora, Wernerfelt (1984) e Barney (1986) contribuíram para o avanço da teoria ao defenderem que uma empresa, para alcançar vantagens excepcionais, deve ser capaz de analisar as informações referentes aos ativos que já controla e que são as competências internas que produzem informações mais precisas sobre o valor de um produto.

Grant (1991) considera os recursos e capacidades elementos centrais para a formulação de estratégias capazes de gerar vantagem competitiva sustentável, por serem eles as principais fontes sobre as quais uma empresa pode estabelecer sua identidade e sua lucratividade. Segundo Barney (1991) e Peteraf (1993) os recursos raros e valiosos são necessários para implementar as estratégias organizacionais e fornecem a base para a criação de valor.

Assim, para a VBR, a vantagem competitiva é alcançada quando empresas criam maior valor econômico que os competidores por meio de produtos e serviços (BARNEY, 1991; GRANT, 1991; PETERAF, 1993). Barney et al. (2003) defende que o valor resulta da aquisição de recursos e da consequente 
transformação desses recursos em produtos ou serviços. Segundo Barney (1991), os recursos é que são valiosos e criam valor.

Conforme Barney et al. (2003), para criar valor, uma empresa deve produzir maiores benefícios que seus concorrentes por meio da diferenciação superior, preço e redução de custos de produtos e serviços. Esse valor e essa diferenciação destacados por Barney et al. (2003) são os principais fatores que levam à criação de valor e consequente vantagem competitiva refere-se à heterogeneidade dos recursos, que é a base da vantagem competitiva porque empresas que detêm os mesmos recursos implementarão as mesmas estratégias, são incapazes de diferenciar-se dos concorrentes (BARNEY et al., 2003).

Collis et al. (1995) reforça este pensamento ao enfatizar a inimitabilidade dos recursos e capacidades como o foco da criação de valor por limitar a concorrência. Segundo os autores, quando uma empresa detém recursos singulares, difíceis de serem esclarecidos e recriados, com uma trajetória pautada na reputação e confiança, obtém vantagem competitiva.

Assim, a heterogeneidade e a inimitabilidade são características que geram mais valor aos recursos porque produzem à empresa maior economia e/ou melhor satisfaz aos desejos dos clientes (BARNEY, 1991; PETERAF, 1993; COLLIS et al., 1995). Portanto, conforme Peteraf (1993), mediante desenvolvimento estratégico de recursos e capacidades é possível o alcance da característica única de recursos e capacidades capazes de entregar aos clientes produtos e serviços que os concorrentes não podem entregar a partir dos seus próprios recursos e capacidades.

Se de um lado a posse de recursos heterogêneos e distintos possibilitam à empresa a criação de valor (PETERAF, 1993), ela só é sustentável e garante vantagem competitiva se os concorrentes não forem capazes de copiar ou obter os recursos e capacidades desenvolvidos, limitando assim os competidores, por não terem acesso aos recursos configurados como únicos e idiossincráticos (BARNEY, 1991).

Neste trabalho, a partir da evidência dada por Barney (1991) de que os recursos-chave e sua incapacidade de duplicação são capazes de criar valor e consequentemente gerar vantagem competitiva, acredita-se que a VBR ofereça bases racionais para a criação de valor para o cliente mediante desenvolvimento de recursos e capacidades estratégicos considerando dois pilares: a heterogeneidade e a não imitação de recursos (BARNEY, 1991).

\section{Recursos e capacidades e sua condição estratégica}

Por recursos, entende-se vantagens, capacidades, processos organizacionais, atributos da empresa, informação, conhecimento, controlados por uma empresa que permitem à ela conceber e implementar estratégias que melhorem sua eficiência e eficácia (BARNEY, 1991). Podem ainda ser definidos como qualquer coisa que possa ser pensada como uma força ou fraqueza de uma dada empresa (WERNERFELT, 1984). Conforme Grant (1991), são os inputs empresariais (equipamentos importantes, patente, finanças, habilidade dos funcionários).

Sob outras perspectivas, recursos são os ativos tangíveis (que podem ser vistos e quantificados) e intangíveis (bens que se encontram enraizados na história da empresa e são acumulados com o tempo) 
(WERNERFELT, 1984). De uma forma mais linear, Amit et al. (1993) considera recursos como ativos capazes de gerar renda para a empresa.

Diversos autores deram definições de recursos que permitem às empresas conceber e implementar estratégias de criação de valor (BARNEY, 2001; KRAAIJENBRINK et al., 2010) e de forma geral, os recursos foram classificados em físicos e humanos (PENROSE, 1954), tangíveis e intangíveis (WERNERFELT, 1984), simples e complexos (HALL, 1992; AMIT et al., 1993), em ativos físicos e intangíveis (COLLIS et al., 1995). Já as capacidades podem ser entendidas como a habilidade de executar alguma tarefa ou atividade, utilizando recursos organizacionais, com o propósito de alcançar vantagem competitiva sustentável (GRANT, 1991). Podem ser definidas como a habilidade de organizar recursos e integrá-los em uma condição desejada (AMIT et al., 1993).

Enquanto os recursos são elementos controlados e de propriedade organizacional, as capacidades dizem respeito ao know how de uma empresa para implantar e combinar os recursos e processos em busca de um objetivo final (AMIT et al., 1993). Segundo Helfat et al. (2003), a capacidade não refere-se apenas à junção de recursos, mas à exploração eficiente dos recursos disponíveis a partir de objetivos específicos, equipes organizadas, que tenham condições de identificar os recursos necessários para desenvolver uma capacidade específica. Helfat et al. (2003) define capacidade organizacional como a habilidade de uma organização de realizar uma série de tarefas utilizando recursos organizacionais com o propósito de alcançar determinado resultado final.

Neste estudo será adotado o conceito de recursos proposto por Barney (2011): recursos são os ativos tangíveis (que podem ser vistos e quantificados) e intangíveis (bens que se encontram enraizados na história da empresa e são acumulados com o tempo) que a empresa controla e são usados para criar ou implementar estratégias. Já o conceito de capacidades, pautará no conceito de Grant (1991): capacidades são a habilidade de executar alguma tarefa ou atividade, utilizando recursos organizacionais, com o propósito de alcançar vantagem competitiva sustentável. Para a sua condição estratégica, será adotado o modelo VRIO de Barney (1991, 2011).

\section{A condição estratégica dos recursos e capacidades}

Decorrente das características de heterogeneidade e não imutabilidade dos recursos e capacidades serem a base para a criação de valor, Barney $(1991,2011)$ identificou as características necessárias para que um recurso seja capaz de gerar vantagem competitiva sustentável, caracterizado de modelo VRIO, utilizado para identificar os atributos estratégicos de um recurso ou capacidade. $O$ modelo sugere que os recursos e capacidades devem ser: valiosos; raros; imperfeitamente imitáveis, ou onerosos para imitar; e capazes de serem explorados pelos processos organizacionais. Segundo Barney $(1991,2011)$ :

O Valor: condição estratégica para explorar uma oportunidade ou neutralizar uma ameaça, de modo a desenvolver uma força organizacional ou uma paridade competitiva. Hitt et al. (2007) ressalta a percepção do cliente para a determinação de valor e a consequente gestão de recursos e capacidades. Para atender o objetivo do trabalho, o elemento valor será analisado a partir do diferencial que o recurso é capaz de prover para o cliente e será descrito na primeira etapa dos resultados; 
A raridade: diz respeito à disponibilidade do recurso no mercado para os concorrentes. Significa ter um recurso único, com características singulares, controlado por apenas algumas poucas empresas concorrentes;

A inimitabilidade: compreende a dificuldade em copiar ou obter determinado recurso (BARNEY, 1991). Se um recurso não permitir imitações, maior será a probabilidade de que qualquer fluxo de lucros que ele venha a gerar seja sustentável (COLLIS et al., 1995);

A organização: considera a exploração e organização dos recursos pela empresa de forma eficiente. Assim, a vantagem competitiva é decorrente da forma como a empresa opera e relaciona os recursos estratégicos. É a exploração e a organização desses recursos que garantem a sustentação da vantagem competitiva (BARNEY, 1991).

Com base neste modelo, as empresas são capazes de identificar e gerenciar seus recursos e capacidades disponíveis, fator importante para a criação de valor e vantagem competitiva sustentável (BARNEY, 2011). Conforme aponta Zubac et al. (2010), são os recursos e capacidades estratégicos de uma empresa as fontes geradoras de produtos e serviços que, adequados às necessidades dos clientes, competem com sucesso no mercado e são capazes de criar valor superior para os clientes.

\section{METODOLOGIA}

Tendo em vista o objetivo da pesquisa, que buscou identificar que recursos e capacidades os médicos de serviços privados da cidade de Rio Verde, Goiás, têm gerido para diferenciar seus serviços com vistas à criação de valor, foi adotado um estudo exploratório descritivo, em função das poucas informações disponíveis sobre o tema e da necessidade da descrição das relações existentes entre os elementos constitutivos (COLLIS et al., 2005): recursos e capacidades estratégicos e diferenciação de serviços privados.

O método utilizado foi o qualitativo, por objetivar descrever as percepções e entender os fenômenos pesquisados a partir de contextos (MERRIAM, 2002) a partir da perspectiva dos participantes (médicos de serviços privados), em suas práticas do dia a dia (FLICK, 2009). Para a coleta dos dados, utilizou-se entrevistas em profundidade com roteiro semiestruturado, previamente organizado a partir da revisão de literatura em consonância com o objetivo do estudo (GODOI et al., 2006). A seleção entrevistados deu-se de modo intencional, por conveniência e acessibilidade, o que facilitou a identificação de indivíduos com experiências e conhecimentos relevantes para o estudo, conforme indica Patton (2002).

Quadro 1: Perfil dos sujeitos.

\begin{tabular}{|l|c|c|c|}
\hline Sujeitos & Sexo & Especialização & Tempo das entrevistas \\
\hline E1 & Masculino & Endocrinologia & 35 minutos \\
\hline E2 & Masculino & Pediatria & 29 minutos \\
\hline E3 & Feminino & Psiquiatria & 33 minutos \\
\hline E4 & Feminino & Dermatologia & 37 minutos \\
\hline E5 & Masculino & Cardiologista & 26 minutos \\
\hline E6 & Masculino & Neurologista & \\
\hline
\end{tabular}

Os critérios utilizados foram: identificar aqueles que já estiveram vinculados a um plano de saúde, mas que atualmente prestam serviços médicos privados na cidade de Rio Verde, Goiás; que tivessem consultórios ou clínicas e com disponibilidade (FLICK, 2009). O tamanho da amostra considerou os objetivos 
da pesquisa terem sido alcançados, pela saturação e redundância dos dados, em que não se encontraram outras contribuição para o estudo. As entrevistas aconteceram no mês de outubro de 2016. Foram entrevistados seis médicos de serviços privados de diferentes especializações. A caracterização é feita por meio do quadro 1.

Para considerar a anonimato dos respondentes, foi utilizada uma referência literal e numérica como técnica para assegurar a confidencialidade das informações utilizadas (GIBBS, 2009). Feita a transcrição integral das entrevistas gravadas, o tratamento e a análise dos dados foram conduzidos por meio da análise de conteúdo (categorização), segundo Bardin (2006).

Nesse sentido, a análise consistiu em descobrir os núcleos de sentido que apoiam o objetivo do estudo. Dito assim, a análise pressupôs três etapas: pré-análise; exploração do material; e tratamento dos resultados, inferência e interpretação. A partir das entrevistas houve o processo de divisão, classificação e ordenação das palavras de acordo com a sua aderência aos significados das perguntas. No tratamento dos dados, foi realizada a análise das categorias, orientadas pelos objetivos, que compreendeu as fases propostas por Bardin (2006): identificação de pontos-chave; formação das unidades de significado; composição das categorias e análise dos resultados. Na categorização foram respeitados, conforme destaca a autora, os critérios de exclusão mútua, homogeneidade, pertinência, objetividade, fidelidade e produtividade.

\section{RESULTADOS E DISCUSSÃO}

A partir das entrevistas, primariamente questionou-se os entrevistados sobre o motivo que os fizeram optar pelo atendimento privado em uma região marcada pelo número significativo de usuários de planos de saúde. Segundo os médicos, a principal razão refere-se à remuneração das operadoras de saúde, conforme o entrevistado E2 "O valor pago pelos planos nos forçam ao atendimento express, pautado em volume, de forma muito mecânica". Além dos aspectos ligados aos preços praticados pelos planos de saúde, os entrevistados E1, E3 e E6 destacaram:

O volume de pessoas, as consultas rápidas me fizeram perceber que os meus pacientes estavam insatisfeito com a rapidez da consulta [...] eles estão fragilizados emocionalmente, precisam de maior atenção (E1);

A relação com os planos de saúde é muito complexa, difícil [...] é como ter um 'patrão velado' [...] tudo é baseado no preço. Infelizmente para algumas especialidades é um mal necessário (E3);

Há uma interferência dos planos de saúde na agenda do médico, na autonomia profissional [...] eles não priorizam a saúde como defendem nos manuais, preocupam-se com o lucro do negócio (E6).

Para atender a condição 'valor' para a identificação dos recursos e capacidades estratégicos, os médicos foram perguntados se tiveram que prover diferenciação nos serviços quando passaram a atender consultas privadas e qual o valor desses ativos. Foram unânimes ao responder que o principal valor, é fruto das expectativas que os clientes criam quando pagam pela consulta, como exemplificado pelos entrevistados. Os principais diferenciais, segundo os entrevistados, partiram de uma observação sobre a própria postura do profissional e de gestão dos seus negócios, conforme destacam alguns médicos. 
Os pacientes quando pagam a consulta querem ver um diferencial. Eles literalmente deixam de ser pacientes e passam a ser clientes. Não dá para entregar o mesmo padrão de consulta. (E1);

O paciente quando paga uma consulta, especialmente o que tem plano, não aceita esses atendimentos rápidos [...] precisamos rever toda a qualidade do serviço (E2);

Esteja certa que eles vêm já esperando alguma coisa diferente. No início percebi que tive que me reformular [...] a forma como a minha equipe trabalha. Rever a agenda. Esse atendimento particular nos força a reconfigurar o nosso serviço (E6);

O fato de saber que o paciente está pagando uma consulta nos faz pensar em outras questões, uma consulta com protocolo mais detalhado, um ambiente mais agradável e estratégico, a forma como a secretária atende esse paciente (E1);

Percebi que antes o meu paciente entendia se a minha agenda atrasava. Hoje ele não entende. Nós e os pacientes temos nos tornado mais exigentes em todos os aspectos. E não se faz nada de diferente se não houver um replanejamento (E2);

Quando decide-se pelo atendimento particular, é um somatório de coisas que vai tornar o serviço diferente. Tive que rever uma série de coisas, o meu próprio atendimento, até a decoração da clínica, o estacionamento (E3);

Eu entendi que não podia atender os clientes com a mesma rapidez. Até a minha forma de conversar, ouvir mais o paciente, teve que mudar (E4);

Para mim aqui foi desenvolver habilidades que nem sempre o médico está capacitado. Tive que contratar treinamento para os meus funcionários. Rever o meu tempo de consulta. $\mathrm{O}$ paciente que paga vem com outros interesses (E5);

Ele quer mais atenção. Além de resolução do problema da qualidade e da eficácia no tratamento, percebo que ele quer uma consulta mais longa, com mais explicações. Estar mais atendo para o horário. É ter a consciência que um consultório não é feito só pelo atendimento do médico (E6).

Para a identificação dos recursos e capacidades estratégicos para a diferenciação de serviços médicos privados, o tratamento das resposta dos entrevistados resultou em quatro categorias constituídas por dois recursos e duas capacidades, conforme o quadro 2, que traz um resumo das categorias de recursos e capacidades.

Quadro 2: Resumo das categorias de recursos e capacidades.

\begin{tabular}{|c|c|l|}
\hline Objetivo & \multirow{2}{*}{ Recursos } & Ambiente físico \\
\cline { 3 - 3 } $\begin{array}{c}\text { Identificar recursos e capacidades estratégicos para a diferenciação de serviços } \\
\text { médicos privados }\end{array}$ & \multirow{2}{*}{ Capacidades } & $\begin{array}{l}\text { Atendimento profissional } \\
\text { colaboradores }\end{array}$ \\
\cline { 3 - 3 } & & Interação com pacientes \\
\hline
\end{tabular}

\section{Ambiente físico}

A primeira categoria identificada pelos entrevistados refere-se ao ambiente e a imagem física do consultório. Está inserido nessa categoria a localização do consultório/clínica, o fato de estar perto de hospitais e ser de fácil acesso; ter estacionamento; investir em equipamentos; o lugar refletir uma imagem favorável, entre outros, a exemplo do que destacam os entrevistados: 'Para oferecer para o meu cliente um serviço privado diferente o médico precisa se preocupar primeiramente com a imagem que seu consultório quer passar. É preciso dar comodidade em estacionar e além de tudo, ser um lugar agradável' (E2); 'Na minha clínica o paciente realiza todos os procedimentos que necessita, sem precisar se descolar. É um diferencial' 
(E5); 'Não adianta eu passar a cobrar pelas consultas e o cliente se deparar com uma clínica como a que eu atendia quando estava num plano' (E6).

Ao analisar as entrevistas sob o ponto de vista da condição estratégica do recurso, apesar da estrutura física e o ambiente estarem disponíveis para todos os competidores, eles são considerados estratégicos a partir da integração dos elementos. Segundo os entrevistados, a depender da especialidade, estar bem localizado em vias de fácil acesso, mas longe de hospitais, representa um problema, por exemplo. Outro exemplo destacado por E4 e que demonstra a importância do conjunto diz respeito aos equipamentos que algumas áreas necessitam. Segundo o entrevistado, 'Preciso pensar no conjunto. Como lido com procedimentos delicados, que podem trazer alguns hematomas, estar numa clínica com pouco movimento, longe do fluxo de pessoas, investir em equipamentos modernos contribui para meu cliente preferir a mim [...] então é um somatório de questões que promovem o diferencial' (E4).

As afirmações corroboram com Barney (1991), em que o diferencial de um recurso está na forma como seus elementos são agrupados e nos investimentos feitos e são esses sistemas integrados que são difíceis de serem imitados e representam a raridade do recurso. Os entrevistados foram unânimes ao afirmar que o investimento que fazem na integração da infraestrutura, localidade, ambiente, equipamentos, pessoal é capaz de refletir os serviços que querem oferecer e de criar diferencial.

Sob a perspectiva do valor do recurso, conforme ressaltou E2, 'a imagem da clínica é capaz de comunicar aos clientes que seus serviços são superiores aos oferecidos pelos concorrentes'. E6 e E1 consideraram que o ambiente e a localização refletem o perfil dos clientes e a percepção deles em relação ao serviço como um todo, conforme destaca E6, 'quando paga a consulta, quer um ambiente mais tranquilo, mais confortável, melhor localizado. Ambientes muito cheios reflete uma imagem diferente da que quero oferecer'.

Quando perguntados sobre como organizam o recurso, os entrevistados afirmaram que estão ligadas à uma reconfiguração que o setor tem passado, demandando os serviços de outras áreas, especialmente as ligadas à gestão. Segundo os entrevistados, nem todos os médicos se atentaram para os investimentos administrativos que a área tem demandado, conforme o exemplo destacado por E1, 'a nossa formação é para os cuidados com a saúde, não em gerir um negócio, com funcionários e demandas administrativas, necessitamos de profissionais especializados'.

Em resumo, percebe-se que isoladamente os elementos que compõem o recurso não são raros e nem difíceis de serem imitados, mas a habilidade de utilizá-lo de maneira integrada e de acordo com as novas demandas desses clientes, que estão dispostos a pagar por consultas, é que configuram essas condições, corroborando com Grant (1991), que defende que os recursos que conferem maior poder de mercado são aqueles possuídos em conjunto.

\section{Conhecimento Profissional}

A categoria que compreende esse recurso intangível refere-se à formação técnica, a experiência e a competência do médico ao oferecer serviços confiáveis e com resultabilidade. Os médicos foram 
consonantes ao afirmarem que sem o conhecimento que dispõem não seria possível realizar seus serviços, por representar a base do negócio.

A partir da possibilidade de gerar vantagem competitiva, os profissionais afirmaram que os médicos precisam ter a consciência de que são aprendizes constantes e é esta atualização que representa o diferencial quando integrado aos demais recursos. Segundo E4, 'o que é contemporâneo hoje, torna-se ultrapassado amanhã e quando falamos em saúde, há sempre novas doenças e novos tratamentos [...] é preciso se atualizar constantemente. Esse é o valor do recurso'.

Para os médicos, assim como destacou o entrevistado E4, o recurso é valioso quando o cliente é capaz de ter confiança no tratamento, no profissional e no serviço como um todo. Segundo E5, 'tratamentos sem excessos, de forma adequada, com bom atendimento, com baixa probabilidade de erros é que vai trazêlo de volta ao meu consultório e fazê-lo falar bem de mim'.

Os entrevistados consideraram que o conhecimento isoladamente não representa raridade, mas a forma como ele é configurado ao longo dos anos, de forma individual e processada pelo profissional, a partir de suas experiências é que representa sua condição estratégica. Segundo E2 'é impossível outro médico copiar o meu conhecimento. Ele pode ter tido a mesma formação, mas as experiências e a forma como processa esse conhecimento é que o torna raro'.

A respeito da organização do recurso, três dos seis profissionais afirmaram que tem dedicado parte dos seus esforços em um trabalho focados em gestão e marketing pessoal, a exemplo de E1, que além de livros publicados, contratou um profissional que o ajuda a elaborar conteúdo focado na sua especialização e no conhecimento que detém para as redes sociais. Segundo o entrevistado, 'são ainda pouco os médicos que tem utilizado ferramentas de gestão para promover sua atividade, seu conhecimento [...] e o marketing pessoal tem se mostrado importante para o meu negócio, me trouxe novos clientes'.

Em resumo, sob o ponto de vista da dinâmica competitiva, conforme ressalta Barney (1991) que os recursos intangíveis são os mais difíceis de serem imitados e são considerados raros por serem mais complexos. Assim, o conhecimento ao ser integrado com outros recursos e capacidades representa uma expertise difícil de ser compreendida (HALL, 1992). Como síntese, considerando as ideias de Hall (1992) e de Hoskisson (1999) sobre o recurso intangível, percebe-se que o conhecimento é valioso por ser difícil de ser interpretado e caracterizado.

\section{Atendimento dos auxiliares e recepcionistas}

Outro importante ativo refere-se à capacidade do corpo de funcionários no atendimento diferenciado. Para os entrevistados, este é efetivamente o primeiro contato que os pacientes terão com o serviço como o todo e a depender da forma como eles são tratados nesse momento, representará sua satisfação total com o serviço. Estão presentes nesta categoria a rapidez e a facilidade em agendar consulta, o interesse dos funcionários, a cordialidade e o profissionalismo.

Os entrevistados E1, E4 e E6 afirmaram que ao migrarem para o atendimento privado, passaram a receber mais reclamações em relação aos colaboradores, demonstrando que os clientes procuravam mais 
dedicação e profissionalismo, configurando, segundo eles, o valor do recurso. E5, a exemplo de outros médicos, afirmaram que suas contratações passaram a ser feita por profissionais especializados, com um perfil diferenciado. A esse respeito, E4 ressalta que tem procurado oferecer aos seus auxiliares treinamento constante para especializá-los no tratamento e relacionamento com o cliente. E5, além de investir também em treinamento, passou a gratificar seu pessoal a partir dos resultados positivos.

Sob a condição estratégica, os entrevistados afirmaram que qualquer profissional tem condições de investir em atendimento, mas poucos o fazem por representar investimentos financeiros e físicos. E5 destaca que 'nada adianta ter um ambiente favorável, o médico ter conhecimento adequado, ter boa relação com o paciente se os funcionários estiverem destoante [...] tudo deve estar em harmonia'. Sobre a diferenciação do recurso, E1, por exemplo, ao perceber que seus pacientes tinham receio de procurar um nutricionista, profissional importante para a eficácia do tratamento, contratou um profissional que atende seus pacientes, sem cobrar pelas consultas, colaborando para o melhor resultado e para a diferenciação de seus serviços.

A organização do recurso, conforme afirmaram os entrevistados refere-se aos processos, critérios e rotinas organizacionais criados e estruturados. Segundo E5 tais características garantem um padrão para as atividades da empresa no que se refere a um serviço diferenciado e com os atributos que o cliente valoriza. Segundo os entrevistados, é importante investir em profissionais para gerir os recursos humanos e treiná-los constantemente, porque 'só assim temos um atendimento diferenciado' (E2).

Conclui-se que o atendimento representa importante capacidade para a diferenciação dos serviços por ser capaz de entregar valor para o cliente e ser o primeiro contato que o cliente tem com o serviço como um todo. A condição estratégica se baseia no investimento e na dependência de pessoas com as habilidades para o atendimento diferenciado. Individualmente as pessoas podem não se configurar como estratégicos, mas a sua combinação com os demais recursos mostrou na prática esta condição (BARNEY, 2011).

\section{Interação com pacientes}

Para a diferenciação dos serviços médicos privados, os entrevistados afirmaram que uma importante capacidade refere-se à habilidade de relacionamento entre médico e paciente. Nesse sentido, E1, E2 e E6 destacaram que o investimento em estratégias que aproximam o médico dos pacientes, especialmente em termos de um atendimento diferenciado e mais humanizado, além de promover maior conhecimento sobre o que o cliente procura ao pagar uma consulta, resulta em confiança. Essa constatação corrobora com o pensamento de Day (1994) que defende que o diferencial de uma empresa está na sua capacidade de identificar o que os clientes valorizam e de posse desta informação, oferecer a eles os produtos e serviços adequados.

Assim, E1 afirma que 'além de resolver os problemas da saúde do paciente, percebi que ele quer atenção, um atendimento mais humanizado'. O entrevistado E2 expõe que para os atendimentos privados, deve-se interagir mais com o cliente, "explicar melhor sobre doenças e tratamentos, demonstrando maior interesse por ele". Para E3 "os clientes querem mais proximidade, estão abalados emocionalmente e em função de desconhecerem a parte técnica do tratamento, querem mais dedicação por parte do profissional". 
Segundo E4 para os clientes pagantes "o atendimento é mais minucioso, com maior explicação para exames, com maior clareza do todo"

Para os médicos, a condição estratégica da capacidade refere-se à esta particularidade e assertividade do compartilhamento das relações entre toda a empresa e cliente e são estas características que representam a raridade e inimitabilidade da capacidade. Segundo Collis et al. (1995), os recursos e capacidades não podem ser avaliados isoladamente, mas na interação com as forças do mercado, por exemplo, ao contribuir para a produção de um produto ou serviço que os consumidores desejem. E5 destaca que 'médicos que são capazes de resolver a maior parte dos problemas do paciente, diferenciando o serviço como um todo é o que vai se destacar e ser escolhido pelo paciente [...] e isso é difícil de ser copiado'.

O exemplo de E1 demonstra a condição estratégica, 'invisto mais tempo nas consultas, faço mais contato físico com pacientes, anoto aspectos pessoais dos clientes, como nome de cachorro, de filho [...] estudo o cliente para aproximar-me deles, procuro demonstrar interesse por ele'.

Sobre como organizam a capacidade, os entrevistados afirmaram estar apoiados em ações/estratégias voltados ao desenvolvimento contínuo dos seus serviços e funcionários na procura de entender melhor esses clientes. Os médicos afirmaram que a gestão das suas empresas passaram a contar com profissionais de outras áreas e neste sentido, alguns tem investido em ações de marketing por entenderem que é esta a área capaz de aproximá-los dos clientes.

Em resumo, parte da entrega de um serviço escolhido pelo cliente provém da capacidade do profissional e sua equipe em diferenciar serviços a partir da relação próxima com o cliente. Isso corrobora com o que destaca Day (1994), que a conexão com o mercado e o relacionamento com clientes são cruciais para organizações que pretendem orientar seus produtos e serviços para o mercado, tornando-os diferenciados em comparação aos dos concorrentes.

\section{CONCLUSÕES}

Com o objetivo de responder a questão de pesquisa 'que recursos e capacidades os médicos de serviços privados gerem para diferenciar seus serviços' constatou-se que, a partir dos recursos e capacidades estratégicos para a diferenciação de serviços privados, os médicos entendem que isoladamente nenhum ativo é capaz de prover diferenciação, mas a integração deles garante vantagem competitiva.

Segundo os entrevistados, a reformulação no ambiente físico, a maior exposição do conhecimento profissional, a diferenciação do atendimento dos auxiliares e recepcionistas e a maior interação com os pacientes representam os recursos mais importantes, mas só são estratégicos, valiosos, raros, difíceis de serem imitados e capazes de serem explorados, se estiverem integrados uns aos outros e se refletirem as expectativas dos clientes que pagam pelas consultas.

Assim, os recursos e capacidades fazem parte de um conjunto de outros recursos e capacidades que garantem a sua condição estratégica. É a forma como eles complementam-se que resulta no serviço que os clientes valorizam. O diferencial está no modo como os recursos e capacidades estratégicos são agrupados. Isoladamente não são necessariamente raros ou difíceis de serem imitados, mas a forma como são geridos, 
integrados aos demais, inseridos na organização e conectados aos clientes é que resulta na sua heterogeneidade.

Ao se considerar a diferenciação de serviços médicos privados, percebeu-se que os recursos e capacidades considerados estratégicos pelos entrevistados foram resultado de uma percepção das expectativas que os clientes têm quando pagam pelas consultas, a exemplo de E1 que afirmou que os desejos dos pacientes mudaram quando passaram a pagar por suas consultas. Segundo os entrevistados, a diferenciação dos serviços requerem maiores investimentos em termos dos recursos e capacidades no que se refere à postura profissional e de gestão do negócio.

Conclui-se que parte da entrega de um serviço escolhido pelo cliente provém da capacidade do profissional e sua equipe em diferenciar serviços a partir da relação próxima com o cliente. A conexão com o mercado e o relacionamento com clientes demonstraram ser cruciais para os profissionais de serviços privados que pretendem orientar suas ofertas para o mercado, tornando-os diferenciados em comparação aos dos concorrentes.

Os resultados do estudo fornecem implicações para a prática administrativa no sentido de auxiliar os médicos na tomada de decisões estratégicas em termos de recursos e capacidades focando no diferencial dos serviços que prestam. Em função das entrevistas terem sido local pode representar limitação para o estudo. Sugere-se, portanto, a exploração dos recursos e capacidades estratégicos para serviços médicos privados em outras regiões.

\section{REFERÊNCIAS}

AMERV. Associação Médica de Rio Verde. Relatório de médicos na cidade. Rio Verde: AMERV, 2014.

AMIT, R.; SCHOEMAKER, P. J. H.. Strategic assets and organizational rent. Strategic Management Journal, v.14, n.1, p.33-46, 1993.

BARDIN, L.. Análise de Conteúdo. Lisboa: Edições 70, 2006.

BARNEY, J. B.. Firm resources and sustained competitive advantage. Journal of Management, v.17, n.1, p.99-120, 1991.

BARNEY, J. B.. Gaining and sustaining competitive advantage. 4 ed. Boston: Prentice Hall, 2011.

BARNEY, J. B.; PETERAF, M. A.. Unraveling the resourcebased tangle. Managerial and Decision Economics, v.24, p.309-323, 2003.

COLLIS, D. J.; MONTGOMERY, C. A.. How do you create and sustain a profitable strategy? Competing on Resources. Harvard Business Review, v.73, n.4, p.118-128, 1995.

COLLIS, J.; HUSSEY, R.. Pesquisa em administração. 2 ed. Porto Alegre: Bookman, 2005.

DAY, G.. Estratégia voltada para o mercado: processos para a criação de valor dirigido ao cliente. Rio de Janeiro: Record, 1994.
FLICK, U.. Desenho da pesquisa qualitativa. Porto Alegre: Bookman, 2009.

GRANT, R. M.. The Resource-Based Theory of competitive advantage: implications for strategy for strategy formulation. California Management Review, v.33, n.3, p.114-135, 1991

HALL, R.. The strategic analysis of intangible resources. Strategic Management Journal, v.13, n.2, p.135-144, 1992.

HELFAT, C. E.; PETERAF, M. A.. The dynamic resource based view: capability lifecycles. Strategic Management Journal, v.24, p.997-1010, 2003.

HITT, M. A.; IRELAND, D. R.; HOSKISSON, R. E. Administração estratégica: competitividade e globalização. São Paulo: Thomson Learning, 2008.

HOSKISSON, R. E.. Theory an research in strategic management: swings of a pendulum. Journal of Management, v.25, n.3, p.417-456, 1999.

KRAAIJENBRINK, J.; SPENDER, J. C.; GROEN, A. J.. The resource-based view: a review and assessment of its critiques. Journal of Management, v.36, n.1, p.349-372, 2010.

MERRIAM, S. B.. Qualitative research and case study applications in education. 2 ed. San Francisco: Jossey-Bass, 2002. 
PATTON, M. Q.. Qualitative research and evaluation methods. Thousand Oaks: Sage, 2002.

PENROSE, E. G.. The theory of the growth of the firm. New York: Wiley, 1959.

PETERAF, M. A.. The cornerstones of competitive advantage: a resource-based view. Strategic Management Journal, v.14, p.179-191, 1993.
WERNERFELT, B.. A resource-based view of the firm. Strategic Management Journal, v.5, p.171-80, 1984.

ZUBAC, A.; HUBBARD, G.; JOHNSON, L.. The RBV and value creation: a managerial perspective. European Business Review, v.22, n.5, 2010. 